\title{
The Role Of Gender Identity In The Behavior Of Bullying
}

Santiago Yubero, Ph.D., University of Castilla-La Mancha, Spain Elisa Larrañaga, Ph.D., University of Castilla-La Mancha, Spain

Tatiana del Río, University of Castilla-La Mancha, Spain

\begin{abstract}
We explore the relation between gender stereotyping in traits and roles and bullying. The sample is comprised by 1835 students (993 boys and 842 girls) from the $4^{\text {th }}$ to $6^{\text {th }}$ grade of Primary school from Castilla-La Mancha (Spain). In order to measure gender roles we have used Sex Role Scale for Children, whilst gender stereotypes have been measured with Children's Personal Attributes Questionnaire. The levels of school aggression have been assessed through Instrument to assess the incidence of involvement in bully/victim interactions at school. The evolution of gender role has a higher significance at work-related than in family roles. In the study of gender traits boys and girls show traditional differential characteristics. Results prove the role of gender stereotypical trait in aggressive behaviour among pairs.
\end{abstract}

Keywords: Gender Stereotypes; Bullying; Students of Primary School

\section{INTRODUCTION}

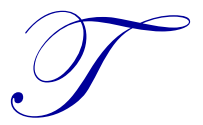

he paradigm of sex/gender assumes that sex refers to physical features that defines people as men and women while gender are social norms to guide behaviours of men and women, so those aspects present different ideals for everyone. Information about features and conducts define in different way men and women and that set up gender stereotypes (Deaux, \& LaFrance, 1998). Those stereotypes about psychological characteristics that are attributes to men and women, are named traits stereotypes; while believes about activities, roles or behaviours that are differenced by sex, are named role stereotypes (William, \& Best, 1990).

Social changes about women role during the last 20 years in Spain are unquestionable and currently ranked $17^{\text {th }}$ in The Gender Gap Index. In the workplace the 53\% of university students are women and so the $40 \%$ of the active population are women too. However those statistics presented by CIS in Spain with 2463 interviews (2008) confirmed that in the Spanish society exists a different distribution of households' task by gender. Thus, while women wash clothes, cooking and cleaning; men perform the home repairs.

Taking into account that gender identity includes how to interact people, it is expected that gender components were linked to the likelihood of engaging in bullying behaviours among peers. Salmivalli and Kaukianen (2004) propose to analyze the differences in aggression as a function of gender role. Similarly, other research has found a relationship between traditional masculine ideology and aggressive behaviour (Japupcak, Lisak \& Roemer, 2002; Ramirez, Andreu \& Fujihara, 2001). Tapper and Boulton (2000) found that older girls' expressive representations are related to decreased expression of aggression.

In a previous study we have a research conducted with 387 adolescents (presented at the IIIrd Conference of Violence in Schools, 2006), and we found a relationship between masculinity and high levels of aggression, as well as a possible influence of femininity as a reducing factor of involvement in aggressive behaviour. Also through qualitative methodology working with 198 teenagers students and 22 teachers and we found masculinity can encourage the use of aggression (Yubero, \& Navarro, 2006). 
Although most studies have been conducted with adults and adolescents the researches with children have shown similar results. Gianluca \& Pozzoli (2006) in a study on the relationship between masculinity and bullying in primary schools (with students from 6 to 10), reported a strong association between the role of an aggressor and masculinity in both sexes.

Considering previous approaches this paper has a twofold objective. The first one is to establish a diagnosis about situation of gender equality among children of elementary and secondary school. The second one is to consider whether gender stereotyping in the system of personal beliefs of children, both in its component trait like role, influences exerted on peer harassment in the school context.

\section{METHODOLOGY}

\section{Participants}

The sample consists of 1835 students from primary education in Castilla-La Mancha. 32.1\% students are from $4^{\text {th }}$ to $5^{\text {th }}$ grade; $32,4 \%$ are from $6^{\text {th }}$ grade. All students are aged between 9 and 12 years old $(9$ years: $31.1 \% 10$ years: $31.4 \% 11$ years: $31.9 \%$, and 12 years: $5.6 \%$ ). They come from 15 different centres, three of each of the provinces of our community, a centre of the capital, another in a town of over 5,000 inhabitants and one from a town of fewer than 5,000 inhabitants.

\section{Instruments}

To measure gender identity scale we use the CPA-Q (Children's Personal Attributes Questionnaire, Hall \& Halberstadt, 1980) on the short version (21 items) that has been recently validated by Thomson and Zand (2005).

To measure gender roles we have applied the Sex Role Scale for Children (Björqvist and Osterman, 1992). It has 21 items, of which 11 have been changed from the adult inventory. This scale was developed for cross-cultural research on attitudes toward sex roles among children.

For the measurement of peer harassment we have used the Instrument to assess the Incidence of Involvement in bully / victim interactions at school (Rigby \& Bagshaw, 2003). This scale provides information about the existence of bullying among peers in the forms of aggression that we have selected for our study (direct physical aggression-FD-FI indirect physical aggression, direct verbal aggression-VD-, indirect verbal aggression-VI and exclusion-Ex). We considered four levels (0 -never, 1 -sometimes 2 -weekly, 3 -daily). For the preparation of this work we used only the subscale of harassing.

\section{Procedure}

Firstly we have administered the test in classroom groups. The administration was collective and regular school hours in a session for the guidance, instructions for completing the questionnaire were given in class before beginning the administration. The test was administered by a member of the research team, with the teacher present without being involved in the process, being the researcher responsible for conducting the necessary clarification to the student who is requested.

We requested the participation of each student stressing the voluntary nature and ensuring the anonymity of their responses with the consent of their parents for collaborating in that study.

\section{RESULTS}

To determine the gender characteristics we used a differential analysis on the average each of the items, so we assigned only as masculine characteristics of those in which the score is higher in the description made by children themselves using a significance level of .001. The same procedure was followed for the characteristics of femininity. The results show different characteristics for each of the components of trait stereotyping. Masculinity is comprised of four features: hard $(M$ boys $=2.46, M$ girls $=2.32, t=2.69, p<.000)$, acts as leader $(M$ boys $=2.06, M$ girls $=$ 
1.83, $t=4.08, p<.000)$, has to be better than others $(M$ boys $=2.18$, Mgirls $=1.98, t=4.02, p<.000)$ and angry $(M b o y s=$ 2.15, $M$ girls $=2.00, t=2.92, p<.001)$. The feminine features are: she loves children $(M$ boys $=3.17, M$ girls $=3.64, t=-$ 9.64, $p<.000)$, sensitive $(M$ boys $=3.44, M$ girls $=3.57, t=-3.14, p<.001)$, obedient $(M$ boys $=2.80, M$ girls $=2.93, t=-$ $2.80, p<.000)$, kind $(M$ boys $=3.13, M$ girls $=3.30, t=-3.99, p<.000)$, compassionate $(M$ boys $=2.46, M$ girls $=2.32, t=-$ $3.99, p<.000)$ and comprehensive $(M$ boys $=3.30$, Mgirls $=3.47, t=-4.21, p<.000)$.

Factor analysis of these characteristics explains that $38.55 \%$ of the variance, grouped into two factors, the first are the characteristics of femininity $(23.82 \%$ of the variance) and the second are characteristics of masculinity $(14.73 \%)$.

What is meaningful is the predominance of masculinity in boys (Mboys $=2.51$, Mgirls $=2.30, t=9.37$, $p<.000)$ and femininity in girls (Mboys= 3.22, Mgirls $=3.42, t=-7.62, p<.000)$. Although for both sexes is the highest value of femininity, this aspect reflects how boys are also ascribed themselves stereotypical characteristics of the other gender. And so, the girls also used to describe themselves instrumental characteristics, which leads to classically masculine traits out of the stereotypical image of gender difference.

In the study of stereotypical role, the factor analysis of the selected items from the SRCS explains $49.84 \%$ of the variance, $33.67 \%$ of family roles and work roles on $16.17 \%$. The results indicate that children maintain a more traditional gender roles, both in work roles $(M$ boys $=0.91, M$ girls $=0.69, t=5.84, p<.000)$ and family roles $(M$ boys $=$ 1.64, $M$ girls $=1.35, t=5.84, p<.000)$. Both for boys as for girls are greater equality in work roles.

The contingency of gender stereotyping features with bullying behaviour have reached a statistical significance $(\chi 2=1320.50, p<.000)$; both in masculinity traits $(\chi 2=41.44, p<.000)$ and femininity traits $(\chi 2=92.24$, $p<.000)$. The gender role stereotyping also has reached significance in the contingency with bullying $(\chi 2=122.72$, $p<.000)$, in work roles $(\chi 2=38.87, p<.000)$ and family roles $(\chi 2=27.92, p<.009)$.

Table I: Comparison of means in aggressive behaviour

\begin{tabular}{|c|c|c|c|c|c|c|c|}
\hline & & \multicolumn{3}{|c|}{ Global sample } & \multicolumn{3}{|c|}{ Gender stereotypes } \\
\hline & & Stereotyping & Other & $t$ & Boys & Girls & $t$ \\
\hline \multirow{4}{*}{$\frac{\overline{0}}{\frac{0}{0}}$} & Masculinity & 1.79 & 1.19 & $5.78 * *$ & 2.05 & 1.18 & $3.62 * *$ \\
\hline & Femininity & 0.82 & 1.58 & $-7.82 * *$ & 1.05 & 0.65 & $3.31 * *$ \\
\hline & Work & 2.16 & 1.31 & $3.93 * *$ & 2.44 & 1.43 & 1.33 \\
\hline & Family & 1.57 & 1.25 & $3.11 * *$ & 1.83 & 1.14 & $3.20 * *$ \\
\hline \multirow{4}{*}{$\theta$} & Masculinity & 0.51 & 0.34 & $5.11 * *$ & 0.60 & 0.30 & $4.30 * *$ \\
\hline & Femininity & 0.27 & 0.43 & $-5.19 * *$ & 0.37 & 0.20 & $3.84 * *$ \\
\hline & Work & 0.59 & 0.37 & $3.16 * *$ & 0.65 & 0.45 & 0.91 \\
\hline & Family & 0.50 & 0.34 & $4.70 * *$ & 0.58 & 0.35 & $3.19 * *$ \\
\hline \multirow{4}{*}{ 厌 } & Masculinity & 0.10 & 0.70 & 1.55 & 0.13 & 0.04 & $2.36 * *$ \\
\hline & Femininity & 0.03 & 0.10 & $-3.75 * *$ & 0.04 & 0.03 & 0.46 \\
\hline & Work & 0.23 & 0.07 & $4.38 * *$ & 0.29 & 0.09 & 1.44 \\
\hline & Family & 0.06 & 0.08 & -0.72 & 0.08 & 0.03 & $1.97 * *$ \\
\hline & Masculinity & 0.56 & 0.39 & $4.56 * *$ & 0.65 & 0.34 & $3.94 * *$ \\
\hline & Work & 0.77 & 0.41 & $4.75 * *$ & 0.89 & 0.45 & 1.83 \\
\hline & Family & 0.51 & 0.40 & $2.90 * *$ & 0.62 & 0.32 & $4.04 * *$ \\
\hline & Masculinity & 0.33 & 0.23 & $3.27 * *$ & 0.35 & 0.28 & 1.02 \\
\hline \multirow{3}{*}{$\nabla$} & Femininity & 0.15 & 0.30 & $-5.05 * *$ & 0.13 & 0.17 & -1.08 \\
\hline & Work & 0.38 & 0.25 & $2.12 * *$ & 0.44 & 0.23 & 1.03 \\
\hline & Family & 0.30 & 0.24 & $2.18 *$ & 0.32 & 0.27 & 0.86 \\
\hline \multirow{4}{*}{$\underset{x}{x}$} & Masculinity & 0.30 & 0.20 & $3.82 * *$ & 0.33 & 0.24 & 1.45 \\
\hline & Femininity & 0.27 & 0.12 & $5.60 * *$ & 0.15 & 0.10 & -1.40 \\
\hline & Work & 0.38 & 0.22 & $2.73 * *$ & 0.45 & 0.22 & 1.15 \\
\hline & Family & 0.24 & 0.21 & 0.96 & 0.28 & 0.17 & 1.88 \\
\hline
\end{tabular}

Note: FD: Direct Physical, FI: Indirect Physical, VD: Direct Verbal, VI: Indirect Verbal, EX: Exclusión

$* \mathrm{p}<.05, * * \mathrm{p}<.01$ 
As we show in Table I stereotyping can affect all behaviours analyzed, only family roles lose significance in the indirect physical harassment and exclusion. Stereotyping in work roles is the highest level of harassment in all forms of harassment, both for boys as for girls. The differences in bullying between boys and girls are gone for indirect verbal bullying and exclusion when comparing only the stereotypical subjects. In comparison equated with sex in harassment of students with job-role stereotype.

\section{DISCUSSION}

Although adolescence is the time course in which adolescents settle the concept of gender, our aim is to know gender stereotyping of students in the last primary cycle. Because in this time they are strengthening their gender development and it is possible to start an intervention on equality.

With regard to gender traits, boys and girls have distinctive features, boys present more instrumental features and girls have more expressive characteristics, so those can confirm the type of stereotypical gender traits. However, girls are adopting characteristics associated with the instrumental dimension so some of the differences in traits considered typically male are disappearing. In our study only remaining differences in instrumentality in four features: hard, leader, dominance over others and aggressiveness. However, girls are considered the same as the independent guys, defending their ideas and persevering. Also the boys are taking expressive features, but still remain feminine differentials. Results confirm that most men still cling to the features established for their gender (Auster \& Ohm, 2000), although both sexes are attributed to themselves more stereotypically feminine traits (Barbera, 2004).

In line with the results obtained with adults, the evolution of gender roles in children is more significant in labour issues, while it is shown that are smaller women's changes in domestic roles, in which remains a dominant women's role that is still very traditional. Still, it confirms gender discrimination even in work roles (White, \& White, 2006). These results reflect the social reality of our context, the incorporation of women to work has been faster than the assumption by man of the household chores.

The results of the contingency between stereotyping and harassment lead us to affirm that adherence to gender stereotypes (both traits as roles) influences on aggressive behaviour (Cohn, \& Zeichner, 2006).

Not surprisingly, children who do not recognize the social changes of gender in context are those that reflect greater bias in gender differences contribute to the maintenance of the status quo and power in relationships. And that may mean that they are the most stereotypical in gender inequality so justifying gender roles inequality (Jost, \& Kay, 2005).

\section{AUTHOR INFORMATION}

Santiago Yubero, Ph.D. in Social Psychology by UNED and Degree in Psychology and Pedagogy by University Complutense of Madrid. Associate Professor in Psychology Department. Faculty of Social Education of Cuenca, University of Castilla-La Mancha (Spain). Research Interest: Process psyco-socials of education, in special social problems in education. Phone +34 902204 100; Fax +34 902204 130; E-mail: Santiago.Yubero@uclm.es

Elisa Larrañaga, Ph.D. in Psychology by University of Castilla-La Mancha and Degree in Psychology by University Autónoma of Madrid. Associate Professor in Psychology Department. Faculty of Social Work of Cuenca, University of Castilla-La Mancha (Spain). Research Interest: Process psyco-socials of education, in special social problems in education. Phone +34 902204 100; Fax +34 902204 130; E-mail: Elisa.Larranaga@uclm.es (Corresponding author)

Tatina del Río, Degree in Psychopedagogy by University of Castilla-La Mancha. Professor in Psychology Department. Faculty of Social Education of Cuenca, University of Castilla-La Mancha (Spain). Research Interest: Process psyco-socials of education, in special social problems in education. Phone +34 902204 100; Fax +34 902 204 130; E-mail: Tatiana.delRio@uclm.es 


\section{REFERENCES}

1. Auster, C.J., and Ohm, S.C. (2000): "Masculinity and femininity in contemporary American society: a reevaluation using the Bem Sex-Role Inventory". Sex Roles, 43, 499-528.

2. Barberá, E. (2004): "Perspectiva cognitiva-social: estereotipos y esquemas de género". In E. Barberá and I. Martínez (Eds.), Psicología y Género (pp.55-80). Madrid: Pearson Educación.

3. Björqvist, K., and Österman, K. (1992): Sex Role Scale for Children. Finland: Abo Akademic University.

4. Cohn, A., and Zeichner, A. (2006): "Effects of masculine identity and gender role stress on aggression in men". Psychology of Men and Masculinity, 7, 179-190.

5. Deaux, K., and Lafrance, M. (1998): "Gender". In D.T. Gilbert, S.T. Fiske, and G. Lindzey (Eds.), The Handbook of social psychology (pp.788-827) (4th ed., Vol. 1). New York: McGraw-Hill.

6. Gianluca, G., and Pozzoli, T. (2006): "The role of masculinity in children's bullying”. Sex Roles, 4, 585588.

7. Graves, K.N. (2007): "Not always sugar and spice: expanding theoretical and functional explanations for why females aggress". Aggression and Violent Behavior, 12, 131-140.

8. Hall, J.A., and Halberstadt, A.G. (1980): "Masculinity and feminity in children: development of the Children's Personal Attributes Questionnaire”. Developmental Psychology, 16, 270-280.

9. Japupcak, M., Lisak, D., and Roemer, L. (2002): "The role of masculine ideology and masculine gender role stress in men's perpetration of aggression and violence in relationships". Psychology of Men and Masculinity, 3, 97-106.

10. Jost, J.T., and Kay, A.C. (2005): "Exposure to benevolent sexism and complementary gender stereotypes: Consequences for specific and diffuse forms of system justification". Journal of Personality and Social Psychology, 88, 498-509.

11. Ramírez, J., Andreu, J.M., and Fujihara, T. (2001): "Cultural and sex differences in aggression: a comparison between japanese and spanish students using two different inventories". Aggressive Behavior, 27, 313-322.

12. Rigby, K., and Bagshaw, D. (2003): "Prospects of Adolescent Students collaborating with teachers in addressing issues of bullying and conflict in schools". Educational Psychology, 23, 535-546.

13. Salmivalli, C., and Kaukianen, A. (2004): "Female Aggression. Revisited: Variable- and person-Centered Approaches to Studying Gender Differences in Different Types of Aggression". Aggressive Behavior, 30, 158-163.

14. Tapper, H., and Boulton, M. (2000): "Social Representations of physical, verbal and indirect aggression in children: sex and age differences". Aggressive Behavior, 26, 442-454.

15. White, M.J., and White, G.B. (2006): "Implicit and explicit occupational gender stereotypes". Sex Roles, $55,259-266$.

16. William, J.E., and Best, D.L. (1990): Measuring sex stereotyping: A multination study. Newbury Park, CA: Sage.

17. Yubero, S., and Navarro, R. (2006): “Student's and teachers' views of gender-related aspects of aggression”. School Psychology International, 27, 488-512. 


\section{NOTES}

